\title{
Controlling Cancer Cell Fate using Localized Biocatalytic Self- Assembly of an Aromatic Carbohydrate Amphiphile
}

\author{
Ricardo A. Pires, ${ }^{\S, \&, *, *}$ Yousef M. Abul-Haija, ${ }^{\#, *}$ Diana S. Costa, ${ }^{\S, \&}$ Ramon Novoa-Carballal, ${ }^{\S, \&}$ Rui L. \\ Reis, ${ }^{\S, \&}$ Rein V. Ulijn ${ }^{\#, \dagger, *}$ and Iva Pashkuleva ${ }^{\S, \&}$ \\ $\S_{3 B}$ 's Research Group - Biomaterials, Biodegradables and Biomimetics, University of Minho, Headquarters of the European \\ Institute of Excellence in Tissue Engineering and Regenerative Medicine, AvePark, 4806-909 Taipas, Guimarães, Portugal \\ ${ }^{\&}$ ICVS/3B's PT Government Associate Laboratory, Braga/Guimarães, Portugal ${ }^{\#}$ Department of Pure and Applied Chemis- \\ try/WestCHEM, University of Strathclyde, 295 Cathedral Street, Glasgow, G1 1XL, UK ${ }^{\dagger}$ Advanced Science Research Cen- \\ ter (ASRC) \& Hunter College, 85 St Nicholas Terrace, City University of New York, New York NY 10027, United States \\ Supporting Information Placeholder
}

\begin{abstract}
We report on a simple carbohydrate amphiphile able to self-assemble into nanofibers upon enzymatic dephosphorylation. The self-assembly can be triggered by alkaline phosphatase (ALP) in solution or in situ by the ALP produced by osteosarcoma cell line, $\mathrm{SaOs} 2$. In the latter case, assembly and localized gelation occurs mainly on the cell surface. The gelation of the pericellular environment induces a reduction of the SaOs2 metabolic activity at an initial stage $(\leq 7 \mathrm{~h})$ that results in cell death at longer exposure periods ( $\geq 24 \mathrm{~h}$ ). We show that this effect depends on the phosphatase concentration and thus, it is cellselective with prechondrocytes ATDC5 (that express $\sim 15-20$ times lower ALP activity compared to SaOs2) not being affected at concentrations $\leq 1 \mathrm{mM}$. These results demonstrate that simple carbohydrate derivatives can be used in an anti-osteosarcoma strategy with limited impact on the surrounding healthy cells/tissues.
\end{abstract}

Molecular self-assembly ${ }^{1,2}$ of peptide amphiphiles, short peptides appended with aromatic ${ }^{3}$ or aliphatic moieties ${ }^{4}$, has been a hot topic in the biomedical field for the last two decades. ${ }^{5,6}$ Designed peptide amphiphiles can be used in the 'bottom-up approach' to create structures that resemble the extracellular matrix (ECM) at both structural and functional levels but are much simpler in composition. ${ }^{7-10}$ In addition to peptides, other selfassembling amphiphilic molecules, including carbohydrate and nucleotide moieties have emerged: for example, carbohydrate derivatives or mixed nucleobase/amino acid/carbohydrate conjugates self-assemble into nanofibres and gel under specific conditions (e.g. presence of certain cations, manipulation of temperature, $\mathrm{pH}$, etc.). ${ }^{11,12}$ Because the self-assembly process is orchestrated by different types of intermolecular interactions (e.g. electrostatic, aromatic stacking, hydrophobic effects, hydrogen bonding), ${ }^{13}$ subtle changes in the chemical structure of the amphiphile can affect the assembly structure and process.

One approach to control and direct molecular self-assembly uses the selective catalytic activity of enzymes. Typically, enzymes remove steric or electrostatic blocking groups from nonassembling amphiphile precursors and generate building blocks at the site of catalysis, in a process known as enzymaticallytriggered or biocatalytic self-assembly. ${ }^{14-16}$ Such systems have been studied for several years because of their selectivity, ability to trigger the assembly under physiological conditions and local- ized action. ${ }^{17,18}$ Usually, the procedure involves recombinant enzymes in vitro by direct addition to the precursor solution, ${ }^{15,19}$ with recent examples of in situ biocatalytic self-assembly that use enzymes present in the intracellular/pericellular environment. ${ }^{14,15,18,20-24}$ Phosphatases have attracted attention because of the abundance of phosphorylation and dephosphorylation reactions that take place in vivo. Especially alkaline phosphatase (ALP) is widely used as a diagnostic and prognostic marker in different pathologies. ${ }^{25}$ ALP is present in highly mineralized tissues and is usually expressed on the basement membrane of osteoblasts. ${ }^{26}$ It is overexpressed in some osteosarcomas ${ }^{26,27}$ making it a valid target for localized anti-cancer therapies. Recently, Xu et $a l^{18}$ reported that enzymatic formation of nanofibers of self-assembled aromatic tripeptide amphiphiles in the pericellular space of cancer cells leads to selective inhibition of the cellular metabolic activity, which depends on the concentration of phosphatases in the biological medium.

Herein, we present an aromatic carbohydrate amphiphile, namely, $\quad N$-(fluorenylmethoxycarbonyl)-glucosamine-6phosphate (1), as alternative substrate in this approach. Carbohydrates are the most abundant biomolecules and represent one of the four building elements of life. ${ }^{28,29}$ In particular, glucose is the main player in the carbohydrate metabolism because it can be converted into all other monosaccharides needed for the glycan biosynthesis. Once internalized by the cell, glucose is activated to the nucleotide glucose-6-phosphate (importantly not permeable to cell membrane) and transported to the Golgi where cell surface and ECM glycans are assembled. ${ }^{28}$ The generated glycans are involved in a plethora of biological events through specific pathways but also by providing mechanical cues to the cells: because carbohydrates are rich in hydroxyl groups they generate highly hydrated gels. The physiological importance of this ability of carbohydrates is highlighted in different tissues and organs, e.g. cartilage tissue is abundant in glycosaminoglycans and as a result 70 to $85 \%$ of the weight of the whole tissue is water. ${ }^{30}$ We therefore hypothesize that carbohydrate amphiphiles open up completely new possibilities as therapeutic platforms complementing the more established peptide-based systems, due to their rich chemistry, gelation ability and roles in biological recognition. The introduction of a carbohydrate moiety will result in the formation of supramolecular hydrogels that share some of the glycan properties, but are much simpler.

We report on the use of $\mathbf{1}$ as a selective ALP substrate for osteosarcoma cells $(\mathrm{SaOs} 2)$. We provide data about the specificity of 
this system by comparative tests using cells with a lower ALP expression profile, namely pre-chondrocytes (ATDC5). Our results demonstrate that the system can be used in an antiosteosarcoma strategy, with limited impact on the surrounding healthy cells/tissues as illustrated in Scheme 1 .

We synthesized $\mathbf{1}$ in one step starting from the hydrochloride salt of glucosamine-6-phosphate and using selective reaction of the amino group. The product was purified by HPLC and characterized by different techniques (Figure S1-S5).
A)

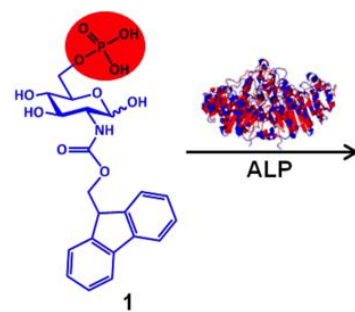

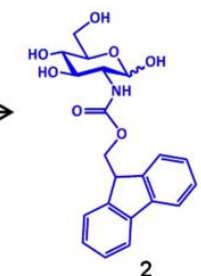

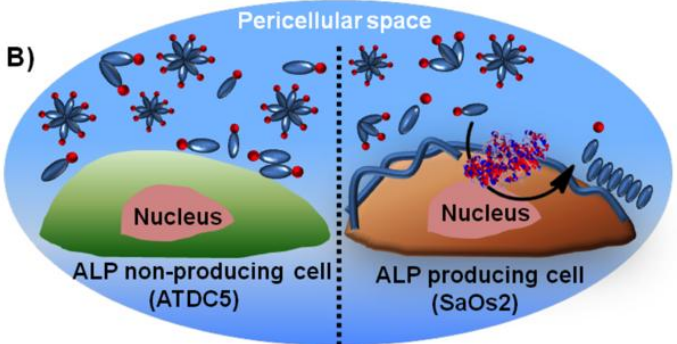

Scheme 1. Illustration of enzymatic transformation of 1 to 2 upon enzymatic activity of phosphatases (e.g. ALP), (A) chemical structures and (B) in situ biocatalytic selfassembly.

Self-assembly and gelation of the precursor $\mathbf{1}$ and the dephosphorylated analogue (i.e. 2) were evaluated using three different concentrations of $\mathbf{1}$ (i.e. 10, 15 and $20 \mathrm{mM}$ ) and different ALP concentrations (i.e. 25, 50 and $75 \mathrm{U}^{£}$ ) in PBS at pH 7.4 (Figure 1). Concentrations of 1 were chosen to be $>5 \mathrm{mM}$, the critical gelation concentration of 2. ${ }^{11}$ Before ALP addition, a transparent solution was observed which was transformed to a transparent gel phase upon ALP addition (Figure 1C inserts). Gelation time varied from $1 \mathrm{~h}$ to $5 \mathrm{~h}$ depending on precursor and enzyme concentrations; gels formed faster when higher precursor and enzyme concentrations were used (gels tested by inverted vial method).
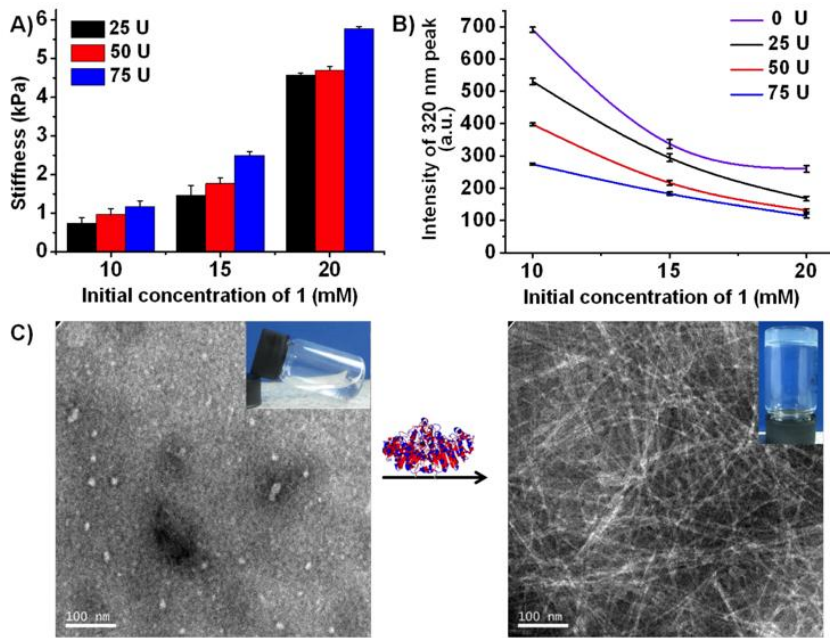

Figure 1. Effect of the concentration of ALP and $\mathbf{1}$ on the (A) mechanical properties (rheology) of the formed hydrogels; (B) supramolecular arrangement of fluorenyl groups observed by monitoring fluorescence intensity of fluorenyl main peak at 320 $\mathrm{nm}$, and C) enzymatic transformation of $\mathbf{1}$ (clear solution of spherical aggregates) to $\mathbf{2}$ (gel of nanofibrous networks) observed by TEM.

HPLC was used to assess the ability of ALP to dephosphorylate 1 and to study the dephosphorylation rate during $24 \mathrm{~h}$ (Figure S6). The conversion rate could be controlled by the enzyme concentration: faster conversion was observed when higher enzyme concentration was used. Similar behavior was previously reported for phosphorylated Fmoc-dipeptide systems. ${ }^{14,31}$

In biocatalytic self-assembly, enzyme kinetics (i.e., the rate of production of self-assembly building blocks) dictate gelation properties, such as supramolecular arrangement and the subsequent gel stiffness. ${ }^{32}$ Therefore, the mechanical properties of the formed hydrogels were evaluated by rheology after $24 \mathrm{~h}$ of ALP addition (Figure 1A and S7). As expected, higher ALP concentrations led to formation of stiffer gels. These observations were directly correlated with fluorescence emission intensities of fluorenyl main peak at $320 \mathrm{~nm}$ (Figure 1B and S8). A clear trend was observed, as $\mathbf{1}$ and/or ALP concentrations increase, the peak at $320 \mathrm{~nm}$ quenches, which suggest more efficient supramolecular stacking within the gel fibers. The morphology of the generated assemblies, involving a supramolecular transformation from spherical aggregates for $\mathbf{1}$ to nanofibers of $\mathbf{2}$ was further characterized by transmission electron microscopy (TEM) (Figure 1C and S9). We observed nanofibrous structures whose network density and resulting gel stiffness can be controlled by either $\mathbf{1}$ or ALP concentrations.

The capacity of the recombinant ALP to induce self-assembly and the previous publications ${ }^{18,33}$ by Xu's group motivated us to investigate this process in situ, in the presence of osteosarcoma cell line (SaOs2) known to overexpress ALP. ${ }^{26}$ The experiments were carried out both in cell suspension (i.e. non-adherent cells) and on cell monolayers in the presence of different concentrations of 1 (0-20 mM). Macroscopic gelation was visible after 2 days of culture when a cell suspension was used. Self-sustained macroscopic gels were observed at longer culture period, i.e. after 4 days of culture (Figure S10A). Gels were formed from solutions of 1 with concentration of 10,15 and $20 \mathrm{mM}$, although, only the gels obtained from the most concentrated solution were easy to further manipulate (Figure 2A).

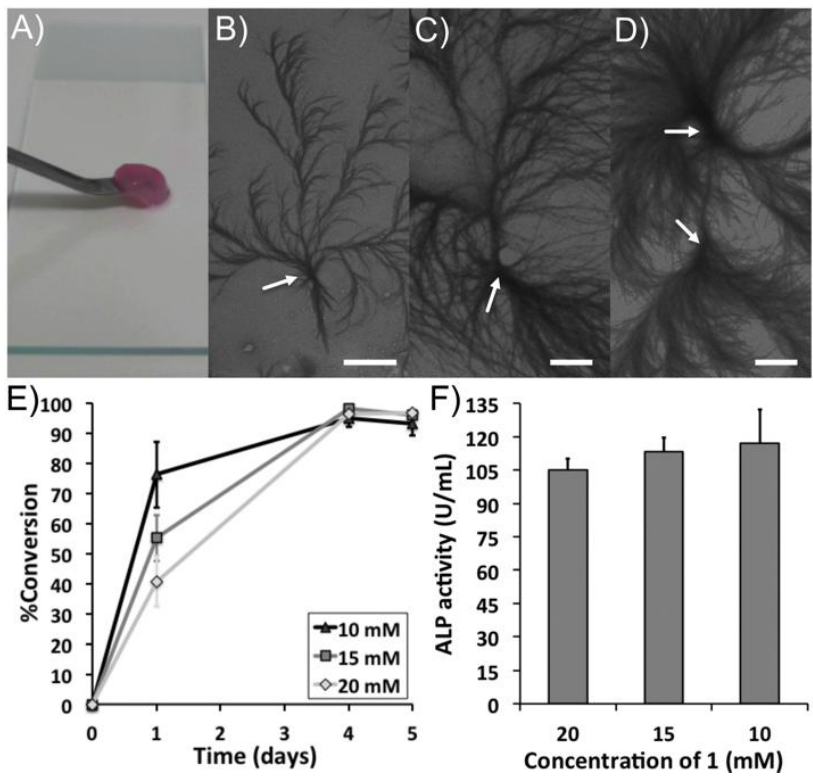

Figure 2. Self-assembly and gelation of $\mathbf{1}$ in SaOs2 suspension: (A) formation of gel is observed after 4 days of culture in the presence of $20 \mathrm{mM}$ of $\mathbf{1}$, (B) SEM images reveal nucleating clusters (white arrows) with (C-D) nanofibers growing in a concentric 
manner and joining with each other, scale bar $=2 \mu \mathrm{m}$. (E) Biocatalytic in situ conversion of $\mathbf{1}$ to 2 executed by the SaOs2 ALP as a function of time and initial concentration of 1. (F) ALP activity after 1 day of $\mathrm{SaOs} 2$ culture as a function of the initial concentration of $\mathbf{1}$.

The gels produced with $20 \mathrm{mM}$ of $\mathbf{1}$ during 4 days of cell culture were collected, dehydrated and analyzed by SEM. The images unveiled nano-fibrillar structures organized around nucleating clusters $^{34}$ (Figure 2B). The density of the nanofibers increased within the clusters (Figure 2C,D), they grew and ultimately joined with the neighboring clusters (Figure S10B). We note that the morphologies of the fibers formed differ depending on the experimental conditions used in the absence (Figure 1C) and presence of the cells (Figures 2B-D). Interestingly, the quantification of the $\mathbf{1}$ to $\mathbf{2}$ conversion (Figure $2 \mathrm{E}$ ) revealed a stable $\sim 7 \mathrm{mM}$ concentration of $\mathbf{2}$ in the medium after 1 day of culture, independently of the added quantity of $\mathbf{1}$. This observation is consistent with the relatively stable ALP activity at all the culture conditions, as confirmed by ALP quantification (Figure 2F). These results confirmed that the ALP produced by SaOs2 is able to convert $\mathbf{1}$ into the nano-fibril-forming 2 .

As expected, the SaOs2 metabolic activity was drastically affected by the dephosphorylation of $\mathbf{1}$ and/or gelation of 2: we measured a metabolic activity below $10 \%$ for all the tested concentrations. Therefore, we designed a different experimental setup aiming to gain insights on the influence of self-assembly and gelation on the cellular behavior. In these experiments, we used a cell monolayer that allows observation of changes in phenotype and cytoskeletal organization. We tested a lower range of concentrations $\leq 1 \mathrm{mM}$ for shorter times of cell culture $(1 \mathrm{~h}$ and $7 \mathrm{~h})$. Moreover, we assayed a second cell line at the same conditions to confirm if the ongoing processes are cell-specific. We have selected the chondrogenic cell line ATDC5 because of two main reasons: (i) ATDC5 present a significantly lower ALP activity when compared to the SaOs2 cells and (ii) the two cell lines, SaOs2 and ATDC5, are usually used as in vitro models of two neighboring tissues, bone and cartilage, making the combined evaluation of both cell types highly relevant.

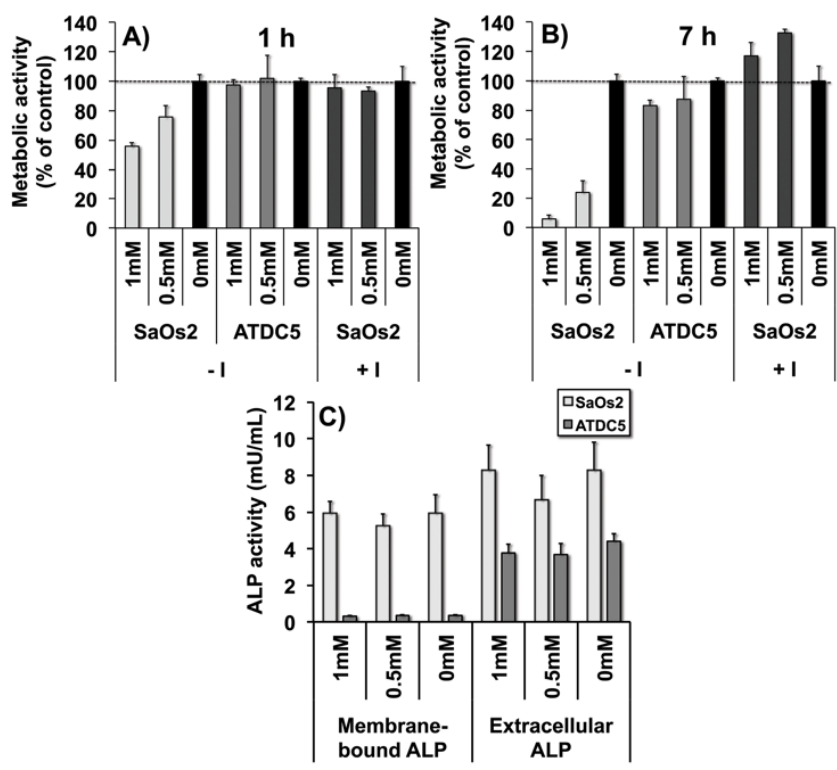

Figure 3. Metabolic activity of SaOs2 and ATDC5 monolayer cultures in the presence of different concentrations of 1 (control $0 \mathrm{mM}, 0.5 \mathrm{mM}$ and $1 \mathrm{mM}$ ), without (- I) and with (+ I) phosphatase inhibitor. Values refer to (A) $1 \mathrm{~h}$ and (B) $7 \mathrm{~h}$ of cell culture. (C) Activity of the membrane bound and extracellular ALP in the
SaOs2 and ATDC5 cell cultures as a function of the concentration of $\mathbf{1}$. Quantification at $7 \mathrm{~h}$ of cell culture.

The metabolic activity of ATDC5 (Figure 3A) was not affected by the presence of $\mathbf{1}$. In contrast, the metabolic activity of SaOs 2 cells reduced drastically at all tested concentrations of $\mathbf{1}$. This tendency is even more pronounced at longer culture times (Figure $3 \mathrm{~B})$. In order to evaluate if this effect is a direct consequence of the higher ALP expression by the SaOs 2 cells, we performed the experiment in the presence of Pierce phosphatase inhibitor. The addition of inhibitor resulted in very similar behavior of SaOs2 and ATDC5 after $1 \mathrm{~h}$ of culture, i.e. no significant reduction of the metabolic activity was observed. After $7 \mathrm{~h}$ of culture, the difference between $\mathrm{SaOs} 2$ cultured with and without inhibitor (Figure 3B) provides clear evidence of a direct relationship between the ALP activity and the cytotoxicity of $\mathbf{1}$.

ALP can be expressed differently within biological systems: soluble, insoluble, membrane-bound, and extracellular ALP. ${ }^{35}$ While the activity of the membrane bound ALP is restricted to the closest pericellular space, the extracellular phosphatase is responsible for the biomolecular phosphorylation in the extended ECM. We quantified both membrane bound and extracellular ALP in the SaOs 2 and ATDC5 cell culture (performed under the same conditions as previously described) in order to evaluate which one is crucial for the observed cytotoxicity.

As expected, there is a distinct difference in the activity of the membrane bound ALP with 15-20 times higher values for the SaOs 2 compared to the ATDC5 cells (Figure 3C). Surprisingly, this drastic difference is not observed for the extracellular ALP. In this latter case, the SaOs2 cells also present a higher ALP activity, although, only by the factor of $\sim 1.5-2.0$. Moreover, the ALP activity is independent of the presence of $\mathbf{1}$ (Figure 3C). These results suggest that the dephosphorylation of $\mathbf{1}$ by the membrane bound ALP is the main responsible for the cytotoxicity of $\mathbf{1}$ towards the $\mathrm{SaOs} 2$ cells.

The conversion of $\mathbf{1}$ to $\mathbf{2}$ by the $\mathrm{SaOs} 2$ cells in their close pericellular space was also confirmed by brightfield microscopy (Figure 4A,B). The images show a layer of gel covering the surface of the cells cultured in the presence of $\mathbf{1}$. SEM was also used to analyze the $\mathrm{SaOs} 2$ cells under the same experimental conditions. The SaOs2 cells exhibited a fibrous network in their pericellular space when $0.5 \mathrm{mM}$ of 1 was used (Figure 4D), while these structures are absent in the control sample (i.e. $0 \mathrm{mM}$ of $\mathbf{1}$, Figure 4C). The density of the fibrous network is increasing at higher concentration of 1 (Figure S11).

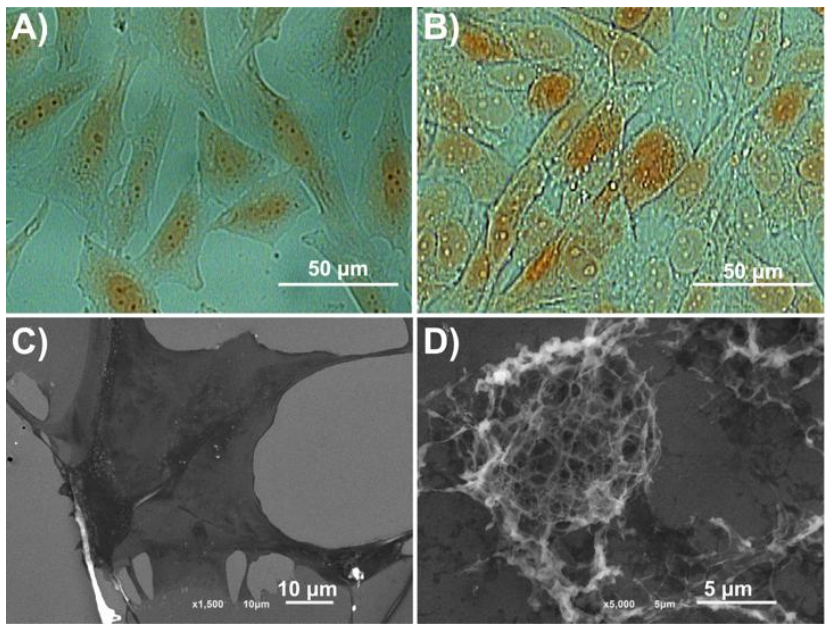

Figure 4. (A,B) Brightfield and (C,D) SEM images of SaOs2 cells, cultured during $7 \mathrm{~h}$, in the $(\mathrm{A}, \mathrm{C})$ absence and $(\mathrm{B}, \mathrm{D})$ presence of $1(0.5 \mathrm{mM})$. 
These results are consistent with the recently reported nanonets of peptide amphiphiles, whose formation is triggered upon dephosphorylation of its derivative by surface and secretory phosphatases in the pericellular environment. ${ }^{18}$ As in the case of peptides, the transformation of $\mathbf{1}$ to $\mathbf{2}$ by the membrane bound ALP leads to the formation of self-assembled "cage-like" hydrogels around SaOs 2 cells. These assemblies may reduce/block metabolite exchange between the cells and thus, they have profound effect on critical cellular activities (e.g. adhesion, motility, proliferation) that ultimately lead to cell apoptosis. ${ }^{36}$

In summary, we demonstrated that a simple carbohydrate phosphate derivative (1) is converted into the self-assembling hydrogelator 2 in situ by the SaOs2 membrane-bound ALP. Upon conversion, 2 generates a cytotoxic nanonet/hydrogel "cage" surrounding the cells. We proved that this process is cell-specific, as other cell types, e.g. ATDC5, with lower membrane-bound ALP expression profiles are not affected by $\mathbf{1}$ at the same concentrations as the ones tested for the $\mathrm{SaOs} 2$ cells. The reported system can be exploited in the development of anti-osteosarcoma strategies. Our data can be further exploited in the design of similar systems sensitive to other types of enzymes that are overexpressed at the pericellular environment of other cancer cells and use them as therapeutic targets. Moreover, the larger diversity of the carbohydrate regio- and stereochemistry, in comparison to the peptidebased systems, opens additional possibilities for the design of amphiphiles with improved gelation and kinetics.

\section{ASSOCIATED CONTENT}

\section{Supporting Information}

Experimental details and characterization data. This material is available free of charge via the Internet at http://pubs.acs.org.

\section{AUTHOR INFORMATION}

\section{Corresponding Author}

* rpires@dep.uminho.pt; rein.ulijn@asrc.cuny.edu

\section{Author Contributions}

\$These authors contributed equally.

Notes

${ }^{\mathfrak{f}}$ Enzymatic activity (U) defined as the amount of enzyme that hydrolyzes $1 \mu \mathrm{mol}$ of 4-nitrophenyl phosphate per min at $\mathrm{pH} 9.8$ at $37^{\circ} \mathrm{C}$;

The authors declare no competing financial interests.

\section{ACKNOWLEDGMENT}

We acknowledge EU (FP7/2007-2013, under grant agreements REGPOT-CT2012-316331-POLARIS; EMERgE/ERC, No. 258775; and ITN ReAd, No. 289723) and the Portuguese FCT, (IF/00032/2013).

\section{REFERENCES}

(1) Lehn, J.-M. Science 2002, 295, 2400.

(2) Whitesides, G. M.; Grzybowski, B. Science 2002, 295, 2418.

(3) Fleming, S.; Ulijn, R. V. Chem. Soc. Rev. 2014, 43, 8150. 20,453

4) Dehsorkhi, A.; Castelletto, V.; Hamley, I. W. J. Pept. Sci. 2014,
(6) Abul-Haija, Y. M.; Ulijn, R. V. Enzyme-Responsive Hydrogels for Biomedical Applications. In Hydrogels in Cell-Based Therapies; Connon, C. J., Hamley, I. W., Eds.; The Royal Society of Chemistry: Cambridge, 2014, p 112.

(7) Kisiday, J.; Jin, M.; Kurz, B.; Hung, H.; Semino, C.; Zhang, S.; Grodzinsky, A. J. Proc. Natl. Acad. Sci. U.S.A. 2002, 99, 9996.

(8) Shah, R. N.; Shah, N. A.; Lim, M. M. D.; Hsieh, C.; Nuber, G.; Stupp, S. I. Proc. Natl. Acad. Sci. U.S.A. 2010, 107, 3293.

(9) Jayawarna, V.; Ali, M.; Jowitt, T. A.; Miller, A. E.; Saiani, A.; Gough, J. E.; Ulijn, R. V. Adv. Mater. 2006, 18, 611.

(10) Mahler, A.; Reches, M.; Rechter, M.; Cohen, S.; Gazit, E. Adv. Mater. 2006, 18, 1365.

(11) Birchall, L. S.; Roy, S.; Jayawarna, V.; Hughes, M.; Irvine, E.; Okorogheye, G. T.; Saudi, N.; De Santis, E.; Tuttle, T.; Edwards, A. A.; Ulijn, R. V. Chem. Sci. 2011, 2, 1349.

(12)Du, X.; Zhou, J.; Guvench, O.; Sangiorgi, F. O.; Li, X.; Zhou, N.; $\mathrm{Xu}, \mathrm{B}$. Bioconjugate Chem. 2014, 25, 1031.

(13) Mendes, A. C.; Baran, E. T.; Reis, R. L.; Azevedo, H. S. WIREs Nanomed. Nanobiotechnol. 2013, 5, 582.

(14) Abul-Haija, Y. M.; Roy, S.; Frederix, P. W. J. M.; Javid, N.; Jayawarna, V.; Ulijn, R. V. Small 2014, 10, 973.

(15) Yang, Z. M.; Gu, H. W.; Fu, D. G.; Gao, P.; Lam, J. K.; Xu, B. Adv. Mater. 2004, 16, 1440.

(16) Ulijn, R. V. J. Mater. Chem. 2006, 16, 2217.

(17) Williams, R. J.; Hall, T. E.; Glattauer, V.; White, J.; Pasic, P. J.; Sorensen, A. B.; Waddington, L.; McLean, K. M.; Currie, P. D.; Hartley, P. G. Biomaterials 2011, 32, 5304.

(18) Kuang, Y.; Shi, J.; Li, J.; Yuan, D.; Alberti, K. A.; Xu, Q.; Xu, B. Angew. Chem. Int. Ed. 2014, 53, 8104.

(19) Toledano, S.; Williams, R. J.; Jayawarna, V.; Ulijn, R. V. J. Am. Chem. Soc. 2006, 128, 1070.

(20) Kuang, Y.; Xu, B. Angew. Chem. Int. Ed. 2013, 52, 6944.

(21) Yang, Z. M.; Xu, K. M.; Guo, Z. F.; Guo, Z. H.; Xu, B. Adv. Mater. 2007, 19, 3152.

(22) Sadownik, J. W.; Leckie, J.; Ulijn, R. V. Chem. Commun. 2011, 47, 728 .

(23) Wang, W. P.; Yang, Z. M.; Patanavanich, S.; Xu, B.; Chau, Y. Soft Matter 2008, 4, 1617.

(24) Yang, Z.; Liang, G.; Guo, Z.; Guo, Z.; Xu, B. Angew. Chem. Int. Ed. 2007, 46, 8216 .

(25)Liu, P. P. L.; Leung, K. S.; Kumta, S. M.; Lee, K. M.; Fung, K. P. Oncology 1996, 53, 275.

(26) Pautke, C.; Schieker, M.; Tischer, T.; Kolk, A.; Neth, P.; Mutschler, W.; Milz, S. Anticancer Res. 2004, 24, 3743.

(27) Randall, J. C.; Morris, D. C.; Zeiger, S.; Masuhara, K.; Tsuda, T.; Anderson, H. C. J. Histochem. Cytochem. 1989, 37, 1069.

(28) Essentials of Glycobiology; Varki, A.; Cummings, R. D.; Esko, J. D.; Freeze, H. H.; Stanley, P.; Bertozzi, C. R.; Hart, G. W.; Etzler, M. E., Eds.; CSH Press: New York, 2009.

(29) Pashkuleva, I.; Reis, R. L. J. Mater. Chem. 2010, 20, 8803.

(30) Mansour, J. M. Biomechanics of cartilage. In Kinesiology: the Mechanics and Pathomechanics of Human Movement; Oatis, C. A., Ed.; Lippincott Williams and Wilkins: Philadelphia, 2003, p 66.

(31) Yang, Z.; Liang, G.; Ma, M.; Gao, Y.; Xu, B. Small 2007, 3, 558. (32) Thornton, K.; Smith, A. M.; Merry, C. L. R.; Ulijn, R. V. Biochem. Soc. Trans. 2009, 37, 660.

(33)Shi, J. F.; Du, X. W.; Yuan, D.; Zhou, J.; Zhou, N.; Huang, Y. B.; $\mathrm{Xu}, \mathrm{B}$. Biomacromolecules 2014, 15, 3559

(34) Hirst, A. R.; Roy, S.; Arora, M.; Das, A. K.; Hodson, N.; Murray, P.; Marshall, S.; Javid, N.; Sefcik, J.; Boekhoven, J.; van Esch, J. H.; Santabarbara, S.; Hunt, N. T.; Ulijn, R. V. Nat. Chem. 2010, 2, 1089.

(35) Anh, D. J.; Dimai, H. P.; Hall, S. L.; Farley, J. R. Calcif. Tissue Int. 1998, 62, 332.

(36)Zorn, J. A.; Wille, H.; Wolan, D. W.; Wells, J. A. J. Am. Chem. Soc. 2011, 133, 19630.

(5) Boekhoven, J.; Stupp, S. I. Adv. Mater. 2014, 26, 1642. 